\title{
An Improved-SRF Strategy for Distribution Grid Connected SPV System for Power Quality Improvement under Non-linear Load Conditions
}

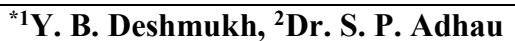 \\ ${ }^{1}$ Datta Meghe Institute of Engineering \& Technology and Researh, Wardha, India \\ ${ }^{2}$ Yeshwantrao Chavan College of Engineering, Nagpur, India \\ Email:sd7088@gmail.com,adhau_sp@yahoo.com
}

Received: 15th October 2019, Accepted: 31st January 2020, Published: 30th April 2020

\begin{abstract}
In few decades, non-conventional energy sources have been consider as the most encouraging source for offgrid power generation. It is challenging task to generate power with renewable sources integrated with grid with improved power quality. In this paper, an improved current control strategy is propose for photovoltaic grid connected system for empowerment of power quality. Also a hybrid PLL is propose in this paper which detects the phase angle with high accuracy. Due to the utilization of power electronic devices, harmonics are produce in system and this one is the major concern which creates the power quality issues. It is also difficult to compensate the effects imposes on system due to non-linear loads. Thus, the priority of this paper goes for the improvement of power quality by simply reducing total harmonic distortion (THD) with maintaining balance source under non-linear load condition. This paper includes some improved features of synchronous reference frame method which leads to a low THD. The propose method is simulated in matlab environment to reveal its fruitfulness.
\end{abstract}

Keywords

Improved Synchronous Reference Frame (ISRF), Phase Lock Loop (PLL).

\section{Introduction}

Photo voltaic energy for power generation is presenting as encouraging source ingredient. Power generation from fossil fuels imposes hazardous effect on our environment. On other hand, energy from other renewable sources are not that much reliable yet. So the energy from sun gives clean and sufficient energy to produce power for the fulfilment of load demand. Most of industrial and commercial areas utilizes PV system on top of buildings to fulfil its power demand which helps urban areas more sustainable. [1-4]

From last few years, PV systems integrated to distribution grid is gaining more attention as it can provide clean energy with reduce cost. In such systems, power electronic converters plays an important role. This type of systems need two controls for two different purpose; one is to track maximum power point under varying irradiance and temperature condition and another one for power quality enhancement. Variation in irradiance and temperature is the main problem in solar panel. It is essential to produce constant power for load and grid under such condition. Thus, different MPPT methods are propose such as perturb and observe method, incremental conductance method, grey-wolf optimisation technique etc. [10]

In this paper, perturb and observe method is use for tracking. It generate pulses for switch place in dc-dc converter. DC-DC converter is use to give constant dc output power. In this paper, three leg inverter is used with interfacing inductance and $\mathrm{RC}$ filter which is utilize to attenuate ripples.

In this paper, improved synchronous reference frame method is propose for grid synchronization with inverter and harmonic current compensation. Synchronization is the main aspect which is to be mainly focus. Mostly PLL is used for synchronization.

It is essential to detect and track accurate phase angle which depends upon choice of PLL There are different PLL strategies such as enhance PLL, decoupled synchronous reference frame PLL, double decoupled synchronous reference frame PLL, [15] stationary reference frame PLL etc. [6-8] But there are some drawback related to this PLL. To overcome this drawback, a new PLL is proposed by combining two different PLL. In this paper, hybrid PLL is used which is a combination of stationary reference frame PLL and synchronous reference frame PLL.[14] Thus, it contain advantages of both the type of PLL and hence can track phase angle more accurately.

The main objective of this paper is:

- To make urban areas more sustainable

- To provide active and reactive power control for grid connected PV system.

- To achieve maximum power from solar energy under varying irradiance and temperature condition using perturb and observe MPPT method.

- To increase use of solar energy for power generation 
Methodology

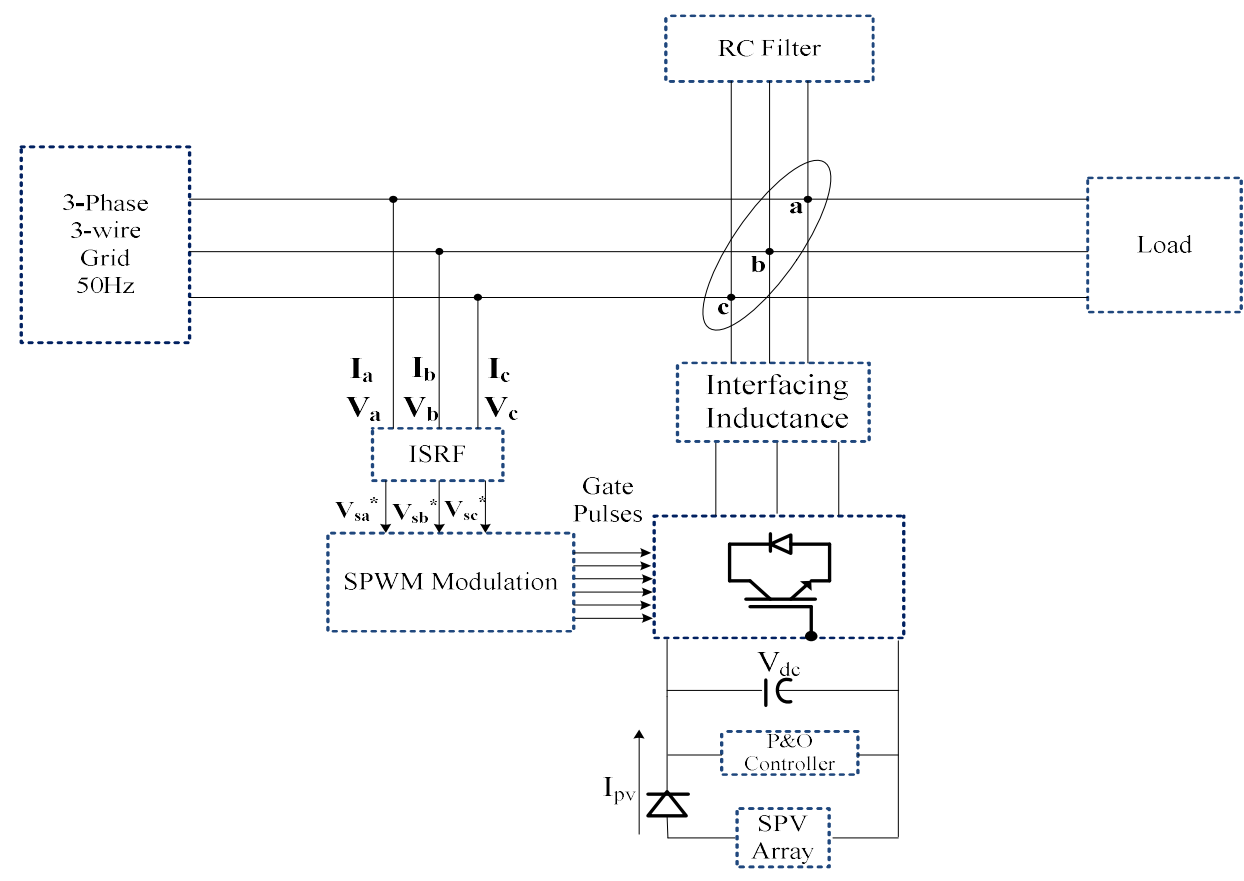

Fig. 1: Architecture Grid Interconnected PV System

The main structure of grid interconnected PV system is shown in fig.1. Here P\&O MPPT method is used to track maximum power under varying irradiance and temperature. [11-12] Filters are used to attenuate ripple caused due to switching of inverter. ISRF is improved synchronous reference frame which is design to control active and reactive power and harmonic distortion under unbalance condition.[13]

\section{Control Scheme}

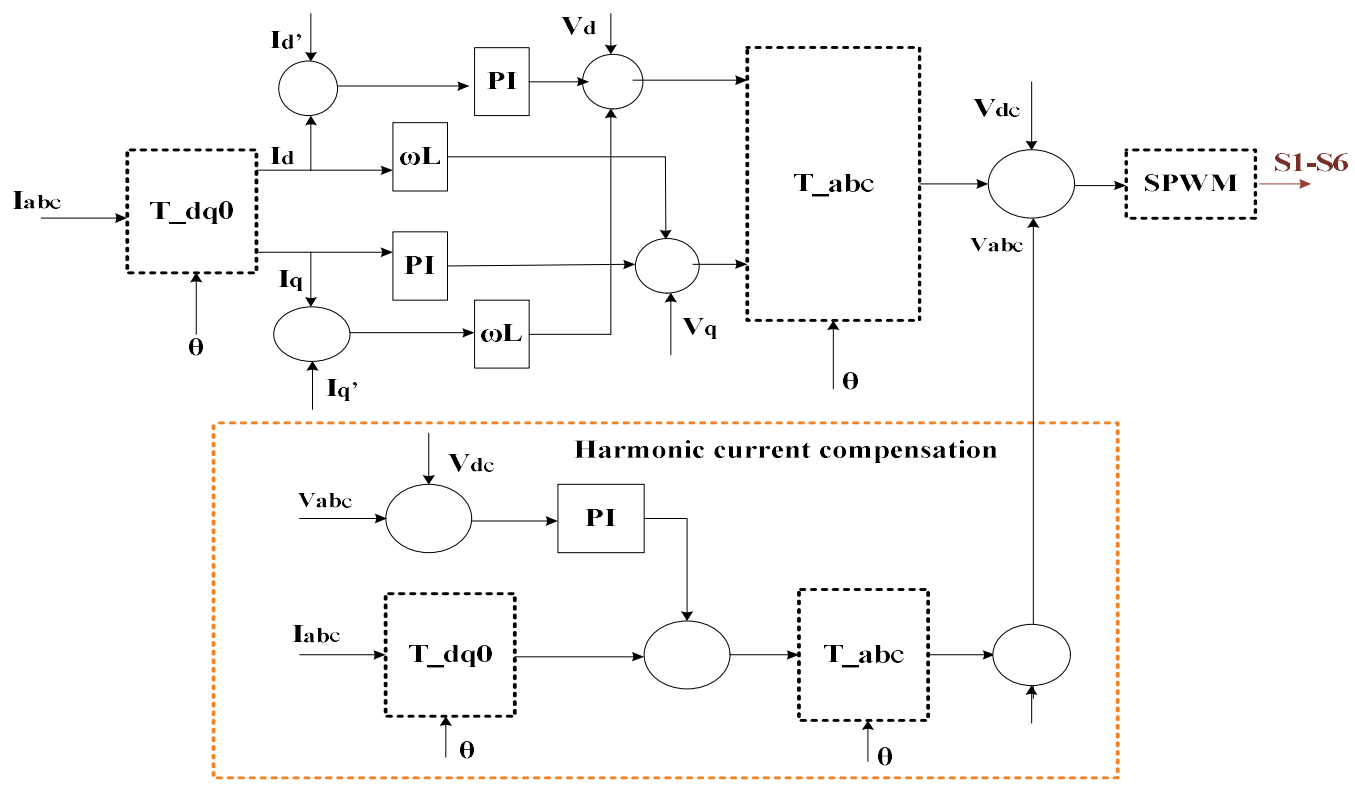

Fig. 2: Improved SRF for Grid Connected PV System

Fig. 2 shows control strategy for grid connected PV system, where, PI controller is used to manage grid current in SRF form. Sinusoidal Pulse width Modulation (SPWM) is used to generate proper pulses for inverter switching. PLL is use to synchronize grid with inverter. In this paper hybrid PLL is use to track accurate phae angle. The reference current in dq form is obtain using the equation: 


$$
\begin{aligned}
& I_{d}^{*}=\frac{P^{*}}{V_{d}} \\
& I_{q}^{*}=\frac{Q^{*}}{V_{d}}
\end{aligned}
$$

The active and reactive power can be given as:

$$
\begin{gathered}
P=V_{d} I_{d} \\
Q=V_{d} I_{q}
\end{gathered}
$$

To detect accurate phase angle, hybrid PLL is used. This PLL is achieved by combining two different PLL i.e. Stationary reference frame ( $\alpha \beta)$ PLL and decoupled double synchronous reference frame PLL. Fig.3 shows hybrid PLL structure.

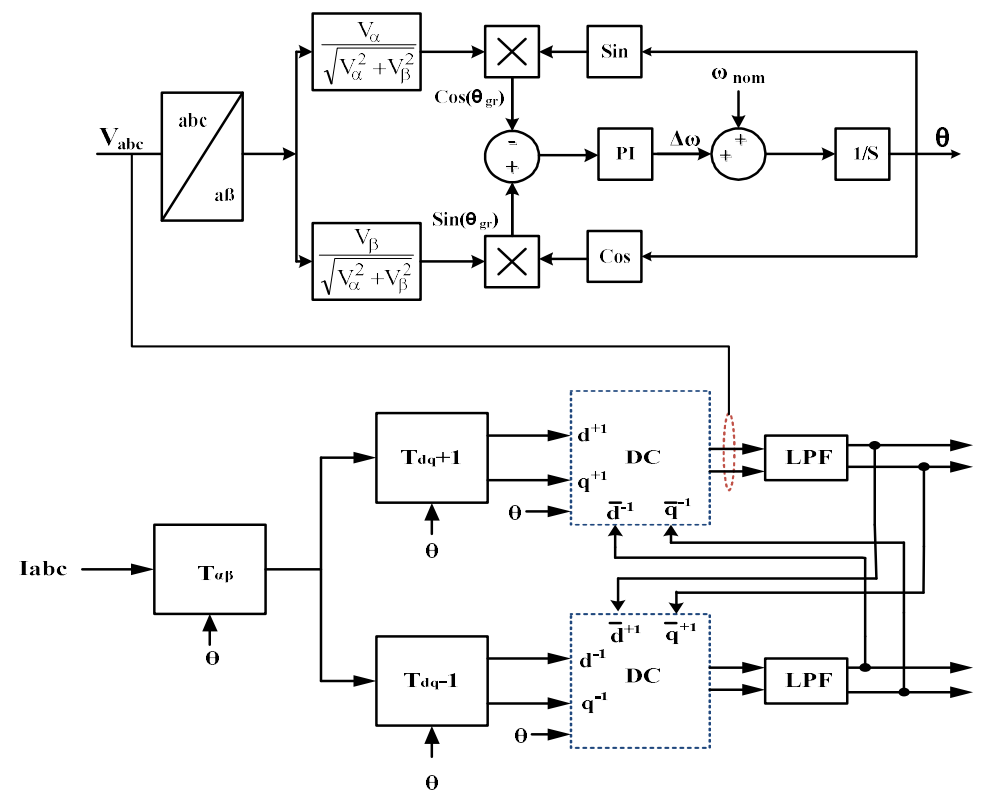

Fig. 3: Hybrid PLL

\section{Results and Discussion}

In the given system, RL type load is utilize with $\mathrm{R}=5 \mathrm{ohm}$ and $\mathrm{L}=100 \mathrm{e}-3$. Load is made unbalance by disconnecting one of the three phase which is also responsible for harmonic distortion. The result are shown in fig. 4 (a) and (b). The unbalance is made for time period of 0.02 to $0.1 \mathrm{sec}$. Phase angle track by hybrid PLL is also shown in fig. 5 

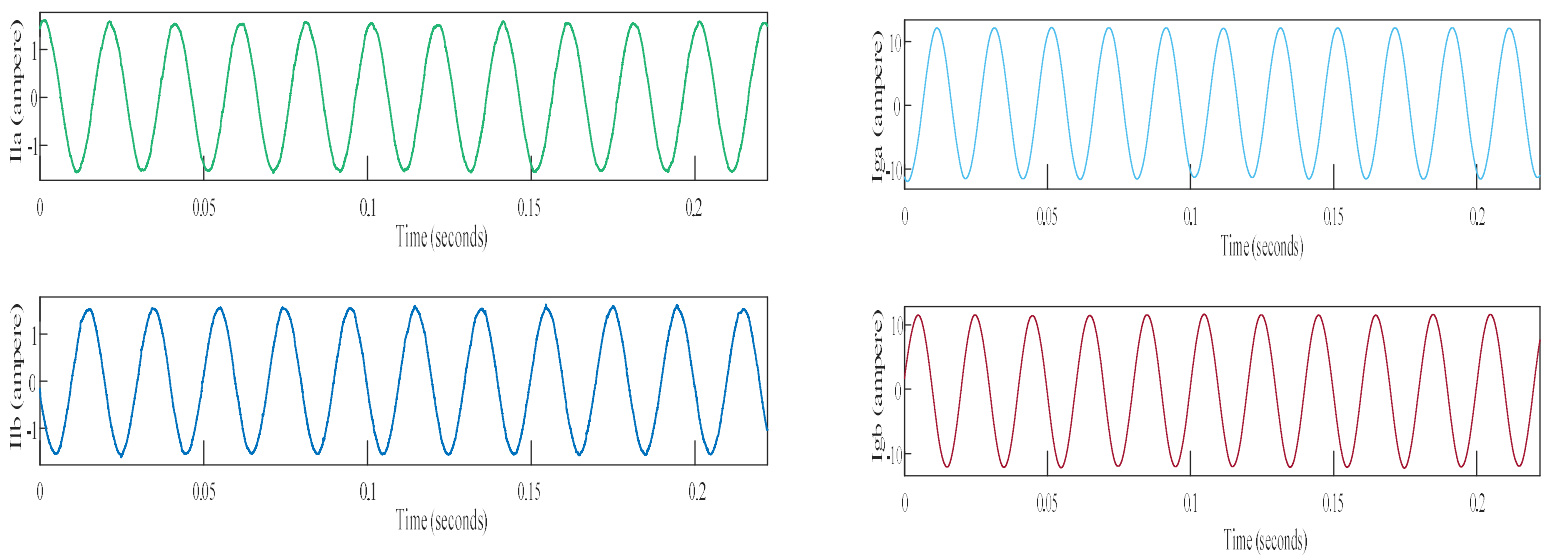

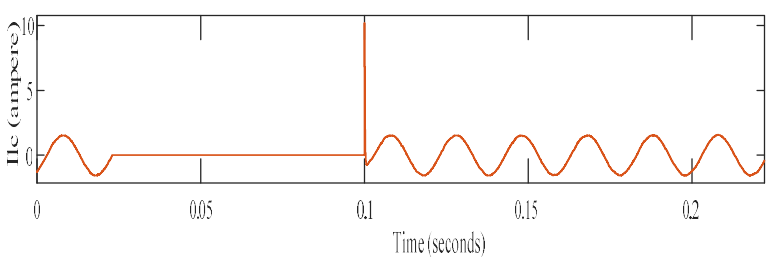

Fig.4: (a) Load Current

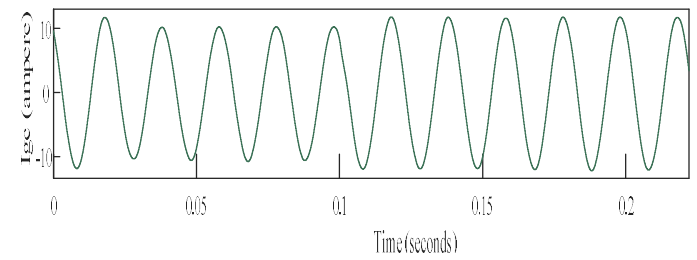

Fig.4: (b) Grid Current

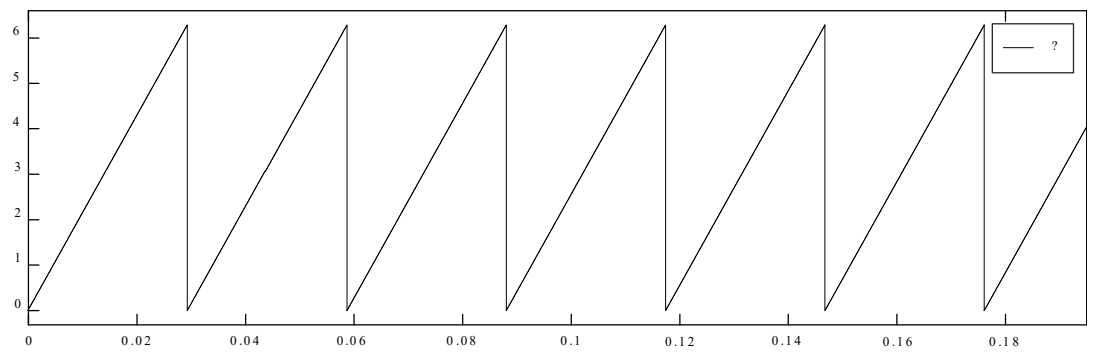

Fig. 5: Phase Angle

In order to realize PV effect, PV model is simulated in MATLAB Simulink and P-V and I-V characteristic is obtained as shown in fig.6.
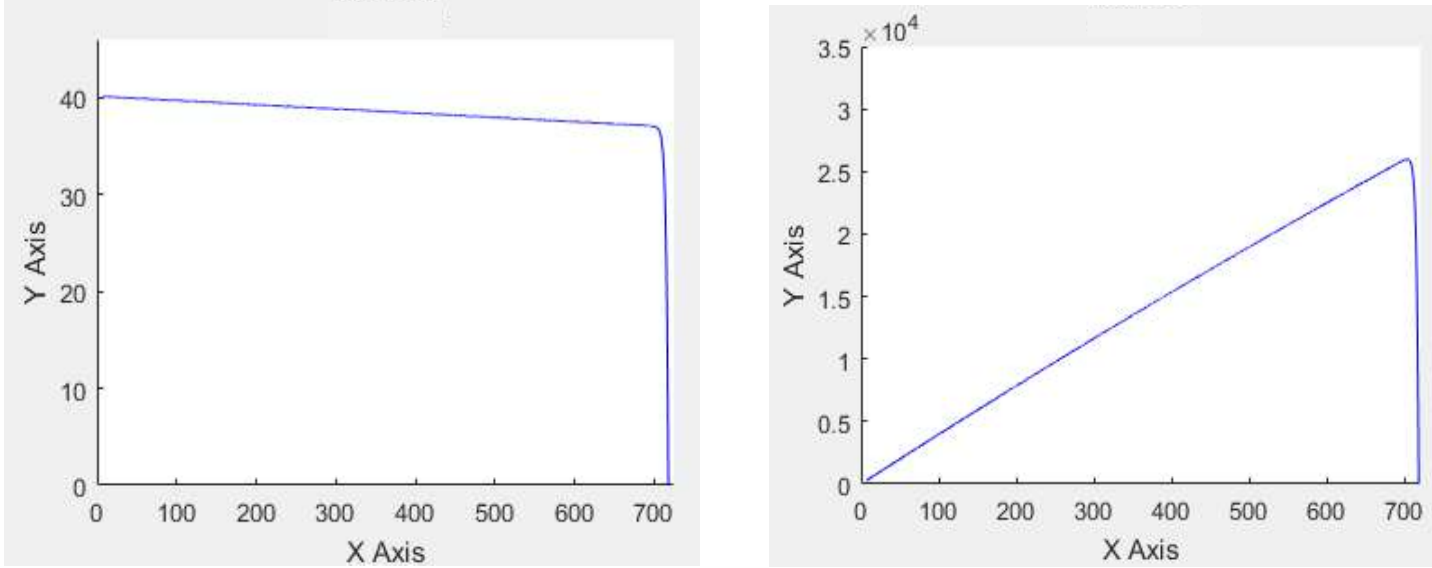

Fig. 6: IV and PV Characteristic 


\begin{tabular}{|c|c|c|}
\hline Phase & $\begin{array}{c}\text { Load Current } \\
\text { (THD\%) }\end{array}$ & $\begin{array}{c}\text { Grid Current } \\
\text { (THD\%) }\end{array}$ \\
\hline Phase a & 2.84 & 2.30 \\
\hline Phase b & 3.02 & 2.55 \\
\hline Phase c & 2.00 & 1.21 \\
\hline
\end{tabular}

Table 1: THD Table

\section{Conclusion}

The distribution grid interconnected to PV system is simulated in this paper using MATLAB software. The PV system is design to provide constant active power supply to the load during day time. An improved synchronous reference frame strategy is given for the control of active and reactive power and total harmonic distortion. By using this control scheme THD reduces to below 5\% and under non-linear condition on load side, the is nearly balance as shown in figure above.

\section{References}

[1] Sekhar, P.C., Mishra, S.: 'Takagi-sugeno fuzzy-based incremental conductance algorithm for maximum power point tracking of a photovoltaic generating system', IET Renew. Power Gener., 2014, 8, (8), pp. 900-914. [2] Muro, M., Saha, D.: 'Why rooftop solar - and full retail feed in tariffs - benefits all consumers', 30 May 2016. Available at http:// reneweconomy.com.au/2016/rooftop-solar-net-metering-is-a-netbenefit 28170.

[3] Espinoza-Trejo, D.R., Bárcenas-Bárcenas, E., Campos-Delgado, D.U., et al.: 'Voltage-oriented input-output linearization controller as maximum power point tracking technique for photovoltaic systems', IEEE Trans. Ind. Electron., 2015, 62, (6), pp. 3499-3507

[4] Kish, G.J., Lee, J.J., Lehn, P.W.: 'Modelling and control of photovoltaic panels utilising the incremental conductance method for maximum power point tracking', IET Renew. Power Gener., 2012, 6, (4), pp. $259-266$. [5] Agarwal, R., Hussain, I., Singh, B.: 'LMF based control algorithm for single stage three-phase grid integrated solar PV system', IEEE Trans. Sust. Energy, 2016, 7, (4), pp. 1379-1387.

[6] P. Rodriguez, A. Luna, R. S. Munoz-Aguilar, I. Etxeberria-Otadui, R. Teodorescu, and F. Blaabjerg, -A stationary reference frame grid synchronization system for three-phase gridconnected power converters under adverse grid conditions, IIEEE Trans. Power Electronics, vol. 27, no. 1, pp. 99-111, Jan. 2012.

[7] P. Rodríguez, J. Bergas, and J. A. Gallardo, “A new positive sequence voltage detector for unbalanced power systems," in Proc. Eur. Conf. Power Electron. Appl., Sep. 2002, [CD ROM].

[8] P. Rodriguez, L. Sainz, and J. Bergas, "Synchronous double reference frame PLL applied to a unified power quality conditioner," in Proc. IEEE Int. Conf. Harm. Power Quality, Oct. 2002, vol. 2, pp. 614-619.

[9] Ms. Manisha Sable, Ms. S.P. Adhau, Dr. R.M. Mohril,“ Integration of natural resource for green power reliability”, International conference on power electronics IEEE IICTE 2012, new delhi, India. 19.

[10] Ms. Mona Marodkar, Mrs. S.P. Adhau, “ Design and simulation of dc-dc converter for photovoltaic system based on MATLAB”,IEEE ICIC,COEP 2015. 20.

[11] Ms. Pooja Bansod, Dr. S.P. Adhau, “ Dynamic modelling and control of hybrid generation system for grid connected application”, ICEETS 2016 Zevier college, nagarcoil, Tamil nadu. 21.

[12] Nagmanaj T. Pathan, Dr. S.P. Adhau, "Design of hybrid wind driven PMSG-solar PV power generation system with single stage converter", International conference on power and embedded drive, SSM college, Tamil nadu, 2017. 22.

[13] Ms. Juhi Gaddam, Dr. S.P. Adhau, “ High tracking efficiency PV energy system”, IEEE ICSEDPS, 2018. [14] Ms. Yashashri B. Deshmukh, Dr. S. P. Adhau,” Mitigation of Power Quality Issues in Distribution Grid Integrated To Photovoltaic-ECS" IEEE ICECA 2019.

[15] Ms. Yashashri B. Deshmukh, Dr. S. P. Adhau, P.G. Adhau, X.R. Pote, V.S. Rajguru," A Enhance PLL Strategy for distribution grid integrated to photovoltaic system for power quality enhancement", JREAS, Vol. 04, Issue 02, April 2019. 